\title{
Cuando la Banda de la Marina Estadounidense tocaba al compás panamericano: esbozo de los albores del intercambio musical en el sistema interamericano (1924-1933)
}

Alejandro García Sudo*

Una versión preliminar del documento que se presenta a continuación se leyó como ponencia el 30 de abril de 2017 en la reunión anual de la Latin American Studies Association (LASA) como parte de la mesa titulada "Repensar el panamericanismo de la primera mitad del siglo XX”. La idea central es que el análisis de la programación y la ejecución de la música que se tocó en actos oficiales de la Unión Panamericana ayudan a concebir el movimiento panamericano como un conjunto de prácticas socioculturales en la esfera pública internacional. El autor comparte el texto como un avance de investigación para dar a conocer algunas de las líneas temáticas de su tesis doctoral en musicología, que defenderá próximamente en la Universidad de California, Los Ángeles (UCLA).

\section{EL PANAMERICANISMO VISTO COMO RED INTELECTUAL TRANSNACIONAL}

Entre 1924 y 1933 se celebraron no menos de 60 conciertos de música latinoamericana en la Unión Panamericana para conmemorar alguna reunión oficial de corte interamericano o la visita oficial de emisarios de América Latina a Washington, D.C., la capital estadounidense. No se trataba de la primera vez que se escuchaba música latinoamericana en Estados Unidos, pero sí fue uno de los esfuerzos más prominentes y sistemáticos por difundir semejante repertorio en ese país hasta ese momento. La serie de conciertos de la Unión Panamericana fue uno de los primeros programas oficiales de

\footnotetext{
* Candidato doctoral en musicología (PhD Candidate), correo electrónico: calejandro@colmex.mx,
} agarcia8@g.ucla.edu 
diplomacia cultural pública destinados a promover relaciones cordiales entre los habitantes de Estados Unidos y América Latina por medio de la música y otras artes escénicas. ${ }^{1}$

No fue un proyecto pasajero o marginal. Decenas de conciertos de música latinoamericana se transmitieron en vivo desde la Unión Panamericana mediante cadenas de radio de onda corta, con pompa y circunstancia, a lo largo y ancho del territorio estadounidense y a veces más allá de sus fronteras. Los conciertos cobraron aún más visibilidad cuando se incorporaron a los rituales anuales del Día Panamericano en 1931 y siguieron siendo populares por décadas. Con todo, la presente reflexión se centra en el periodo 1924-1933. La razón principal de acotar la narrativa a esos años es la necesidad de subrayar que fue en la fase temprana del periodo de entreguerras que se empezó a promover una conciencia panamericana con ayuda de música latinoamericana. Otra razón es que el periodo 1924-1933 coincide con la etapa culminante de la carrera de Franklin Adams, el Consejero de la Unión Panamericana que inauguró y coordinó la primera serie de conciertos de ese organismo.

El ingeniero Frank Adams creció en la ciudad de Stockton, a unas horas de San Francisco. Él y su esposa, Harriet Chalmers, se percataron de la vastedad de América Latina cuando visitaron el México porfirista en un viaje de trabajo. Una gira turística por Perú y otros países sudamericanos acabó de cambiar el derrotero de sus vidas. A su regreso a Estados Unidos en 1909, Chalmers y Adams prepararon transparencias y cortometrajes con escenas de la vida cotidiana de varios de los países que habían visitado y dieron una serie de entretenidas conferencias acerca de la historia y geografía de América Latina. Causaron enorme sensación. A partir de entonces, Chalmers se embarcó en una destacada carrera como viajera, educadora y directora de sociedades geográficas, mientras que Adams aceptó el puesto de asesor y editor de la versión en inglés del Boletín de la Unión Panamericana, la publicación principal de la Unión Panamericana. En 1919, Adams fue designado Consejero de esa organización en Washington. Su tarea era fungir como anfitrión de eventos diversos, cultivar las relaciones públicas de la

${ }^{1}$ La última vez que estos conciertos fueron el tema de una investigación académica fue en 1943 (Pereira Salas, Notes on the History of Music Exchange between the Americas before 1940). Por diplomacia cultural pública me refiero a esfuerzos gubernamentales de concientizar e involucrar a la ciudadanía en debates de política internacional mediante iniciativas de índole educativa, cultural o artística; es una práctica que en Estados Unidos se remonta a los años de la Gran Guerra, bajo influencia Wilsoniana. Véase Graham, Culture and Propaganda..., pp. 1-12. 
Unión Panamericana y promocionar las actividades de dicho organismo haciendo llegar información, materiales educativos y diapositivas con imágenes de América Latina a revistas, escuelas, clubes de mujeres y otras organizaciones civiles en Estados Unidos y el extranjero. En 1924, Adams se percató del potencial educativo y propagandístico de la música y echó a andar la serie de conciertos de la Unión Panamericana.

Dicha serie musical se presentó siempre como una iniciativa conducente al entendimiento intercultural entre naciones americanas. Su propósito era promover relaciones internacionales amigables, dando a conocer la música contemporánea y el folklor musical característico de los distintos países latinoamericanos a la población estadounidense. En la práctica, los conciertos de la Unión Panamericana eran eventos sociales en los cuales integrantes del cuerpo diplomático latinoamericano residentes en Washington se reunían e interactuaban con diversos representantes del Estado mayor y la comunidad empresarial estadounidense. Esto sucedía unas cinco o seis veces cada año. En cada ocasión, el Consejero Adams extendía invitaciones a cientos de miembros prominentes de la sociedad capitalina y daba publicidad al evento en la prensa, la radio y otros medios de alcance nacional e internacional. El material promocional de los conciertos solía girar en torno a la llegada a Washington de músicos de origen latinoamericano que aparecían con cierta frecuencia en los escenarios de Nueva York y otros centros culturales de Estados Unidos o que estaban de paso por la capital como parte de sus giras artísticas en Europa y América.

La evidencia documental indica que Adams y sus amistades en el cuerpo diplomático latinoamericano contactaban e invitaban personalmente a cada uno de estos intérpretes solistas, en su mayoría pianistas, violinistas y cantantes de ópera. Juntos preparaban un programa de canciones y piezas orquestales en el que se destacaba el repertorio característico del país de origen del solista en turno, pero en el que también se procuraba incluir al menos un número musical representativo de las demás regiones de América Latina. Así, los conciertos de la Unión Panamericana sirvieron como un espacio promocional y un punto de encuentro para músicos particulares a la vez que promovieron una imagen de igualdad y hermandad simbólica entre todos los países del continente.

Simultáneamente, los conciertos de la Unión Panamericana fueron ocasiones para exaltar la labor y creatividad musical de compositores latinoamericanos del pasado y el presente. En concreto, la Unión Panamericana brindó un foro privilegiado a compositores latinoamericanos que habían comenzado a gozar de prestigio nacional e internacional a comienzos de la década de los veinte y que, en varios casos, aprovecharon sus conexiones políticas para 
promocionarse en Washington y otras ciudades estadounidenses. Entre los compositores cuya obra se dio a conocer regularmente en la Unión Panamericana destacaron el cubano Eduardo Sánchez de Fuentes, el haitiano Justin Elie, el mexicano Manuel María Ponce, el guatemalteco Jesús Castillo, el nicaragüense Luis Abraham Delgadillo, el colombiano Emilio Murillo, el peruano José Valle Riestra y el chileno Enrique Soro. Nótese que esta ola de promoción musical de ambiciones continentales se suscitó antes de que compositores latinoamericanos más jóvenes y hoy día mejor recordados, como el mexicano Carlos Chávez, entraran en el radar del movimiento panamericano oficial durante la década de los treinta. Así, estos conciertos son útiles para estudiar una etapa temprana y relativamente poco estudiada de la difusión internacional de diversas escuelas de composición latinoamericana, y también para entender el papel del mecenazgo panamericano en la conformación de redes hemisféricas de compositores y sus promotores. ${ }^{2}$

Como en el caso anterior, la evidencia documental indica que Adams y sus asistentes en la Unión Panamericana desempeñaron un papel importante en la conformación de lazos internacionales de comunicación y sociabilidad al recopilar la música de decenas de compositores latinoamericanos. En algunos casos, Adams adquirió personalmente partituras de la música que estaba de moda en Sudamérica durante sus viajes a esa región del continente. En otros casos, los compositores latinoamericanos hicieron llegar copias de sus manuscritos originales al consejero, auxiliados por agentes diplomáticos que iban y venían de Washington. Para mediados de los años treinta, la Unión Panamericana tenía una de las colecciones más grandes de música latinoamericana en Estados Unidos. Algunas partituras de esa colección formaron parte de los paquetes informativos que Adams distribuyó a escuelas, clubes de mujeres y demás instituciones educativas, lo cual sugiere que parte de la obra musical de estos compositores estuvo disponible en cientos de bibliotecas en Estados Unidos.

${ }^{2}$ Eduardo Devés habla de "redes intelectuales transnacionales" como espacios de socialización metanacional que permitieron a sus miembros operar con cierta autonomía del Estado. Véase la "Introducción" a Pita González (comp.), Redes intelectuales transnacionales en América Latina durante la entreguerra, p. 11. En el caso del panamericanismo, sin embargo, nos topamos con una red intelectual amparada por un organismo internacional y avalada por regímenes y actores gubernamentales oficiales. 


\section{EL PANAMERICANISMO VISTO COMO RITO PROPULSOR DE CULTURA CÍVICA}

El hecho de que ni siquiera los especialistas estemos plenamente al tanto de la vida y obra de muchos de los compositores latinoamericanos mencionados anteriormente y de su proyección internacional se debe a deficiencias metodológicas e historiográficas que vale la pena enumerar. La primera deficiencia es la falta de una visión más descentralizada de los procesos culturales transnacionales, es decir, la que se deriva del hecho de que muchas historias siguen escribiéndose bajo premisas nacionalistas que impiden visualizar desarrollos que fueron en verdad regionales. ${ }^{3}$ En el campo de estudio musicológico hay aún poca conciencia de la globalización temprana del quehacer musical latinoamericano y de las transculturaciones resultantes. También hay relativo desinterés por escenas musicales cuyos epicentros no fueron París o Nueva York. Es sólo en años recientes que se han empezado a hacer estudios de la música en Washington, por ejemplo.

La segunda deficiencia resulta de desatención de los musicólogos y otros especialistas a prácticas musicales que entraron en desuso hace ya muchas décadas. Me refiero a repertorios de principios de siglo Xx que no percibimos ni como "clásicos" ni como "populares" bajo nuestras definiciones actuales y que por lo mismo no forman parte de los cánones musicales que nos son más familiares. Vemos en el Apéndice A, por ejemplo, un programa representativo del tipo de música que se programaba cada tres o cuatro meses en la Unión Panamericana. Nos topamos ahí con un potpourri de marchas, canciones y bailes populares, arreglos instrumentales, arias operáticas y piezas de salón de distintos países, géneros y épocas. El público que acudió al concierto de la Unión Panamericana del 21 de abril de 1930 tuvo oportunidad de escuchar un pasillo tradicional interpretado en la marimba en honor al presidente electo de Colombia; un "Inca Step" del peruano Carlos Valderrama, una de varias piezas para bailar que fueron exitosas por su forma de conjugar ritmos tradicionales andinos y sensibilidades jazzísticas; canciones románticas de México y otros países de habla hispana interpretadas por Manuel Salazar, tenor costarricense que alcanzó gran fama en Estados Unidos en esos años; un par de composiciones originales para piano de Luis Abraham Delgadillo, el otro solista invitado de la noche; un

\footnotetext{
${ }^{3}$ Para una crítica de la centralidad desmedida de la perspectiva estadounidense en estudios de historia continental americana, véase Gienow-Hecht, "Decentering American History", Gienow-Hecht (ed.), Decentering America, pp. 1-22.
} 
extracto de una ópera de Carlos Gomes, vetusto compositor brasileño de gran fama internacional cuya música apareció virtualmente en todos los conciertos de la Unión Panamericana; y composiciones orquestales de corte modernista que develan el creciente interés de los músicos y el público de su época por el exotismo de las corrientes indigenistas en América Latina: una "Danza Yaqui” de México, un "Minuet Maya” de Guatemala, una "Danza y Ritual” haitiana, poemas sinfónicos inspirados en "Espíritus incaicos” y pregones callejeros chilenos. ${ }^{4}$

Si tomamos prestado un concepto clave de la obra del historiador y musicólogo William Weber, podemos llamar "variedad" o "miscelánea” a este tipo de programación musical ecléctica, que contrasta con la práctica de las salas de concierto de la actualidad donde predomina más bien el canon de la música clásica europea (i.e., obras dieciochescas y decimonónicas de compositores que se formaron en la tradición musical de los países de habla alemana). ${ }^{5}$ La miscelánea musical era frecuente en las salas de conciertos de muchos países a principios de siglo XX. Se consideraba un tipo de concierto edificante porque daba pie a que distintos individuos — profesionales y no tan profesionales- participaran de viva voz en la escena musical de su localidad y compartieran sus habilidades musicales y repertorios personales con la comunidad.

Este fue el caso de la escena musical que cobró forma en la Unión Panamericana a mediados de la década de los años veinte. Quienes participaron en esos conciertos estaban interesados ante todo en dar a conocer el talento de músicos latinoamericanos de actualidad, muchos de ellos presentes en Estados Unidos en ese momento. Los asistentes sabían que estaban participando en un evento mediático y diplomático cuyo propósito era celebrar públicamente la música de sus colegas, así que no necesariamente esperaban escuchar la música más consagrada o sofisticada. Aunque ciertamente había interés de dar a conocer música distintiva o exótica de América Latina, era igualmente importante hacer gala de la variedad del quehacer musical latinoamericano, tan cosmopolita como el de otras partes del mundo, y celebrar el despliegue de las Bellas Artes del continente en aras de la convivencia civil, la amistad internacional y el deleite espiritual de los asistentes. El resultado: conciertos de naturaleza variable cuya calidad dependía del talento dis-

${ }^{4} \mathrm{El}$ interés estadounidense por las corrientes indigenistas de la música mexicana y latinoamericana se discute en Hess, "Carlos Chávez and Ur-Classicism”, Hess (ed.), Representing the Good Neighbor..., pp. 31-38.

5 Weber, The Great Transformation of Musical Taste, pp. 13-17. 
ponible en cada temporada. Se mezclaban repertorios antiguos y modernos y convivían el academicismo, el modernismo, el virtuosismo, el entretenimiento ligero e incluso ciertas prácticas de aficionado.

Si esta clase de programa no satisface nuestros gustos o expectativas modernas es quizá por una tercera deficiencia analítica que vale la pena señalar aquí, a saber, la falta de conocimiento de la labor política, social y cultural que este tipo de repertorio desempeñó entre su público histórico. Tal carencia tampoco sorprende. Es sólo en años recientes que los musicólogos han dialogado seriamente con los estudiosos del teatro y de los Performance Studies, una disciplina académica en el que las investigaciones y reflexiones ya no se centran en la naturaleza estética o valor intrínseco de un texto, musical o de cualquier otro tipo, sino en los usos y enunciaciones del mismo, así como en los entendimientos y las relaciones socioculturales que se derivaron de tales enunciaciones en un momento determinado. Desde este punto de vista, no importa tanto lo que se lee textualmente en una partitura musical, sino lo que se buscaba lograr con su ejecución en cada ocasión -las ideologías que promovía, las comunidades que conformaba. ${ }^{6}$ En nuestro caso, por ejemplo, lo que se ha venido sugiriendo es que hace falta entender mejor la función política y diplomática de la música que figuró por primera vez en proyectos engalanados con retórica panamericana. ${ }^{7}$

El programa musical del Apéndice A, junto con muchos otros similares entre 1924 y 1933, aporta pistas importantes en este sentido. Como puede observarse, buena parte de los arreglos musicales que se presentaron en la Unión Panamericana corrieron a cargo de músicos provenientes de tres importantes bandas militares estadounidenses cuya sede está en Washington, D.C.: las Bandas de la Marina, del Ejército y de los Marines. Estas agrupaciones tocaban toda clase de géneros musicales, incluyendo marchas, arreglos sinfónicos, arias de ópera, canciones y bailes tradicionales y del momento. Hoy prestamos poca atención a las actividades culturales de los estamentos militares, pero cien años atrás las bandas militares eran agrupaciones harto respetadas que figuraban mes a mes en el entretenimiento popular de la población y en ceremonias de talla nacional e internacional. Las

${ }^{6}$ Madrid, "Why Music and Performance Studies? Why Now?: An Introduction the the Special Issue", <http://www.sibetrans.com/trans/article/1/why-music-and-performance-studieswhy-now-an-introduction-to-the-special-issue> consultado el 20 de noviembre de 2018.

${ }^{7}$ Cabe señalar que la diplomacia misma puede entenderse como un tipo de performance, es decir, como una serie de actos o enunciaciones cuya labor es modificar las percepciones y disposiciones culturales del bando aliado o enemigo. Véase Ahrendt, Ferraguto, Mahiet (eds.), Music and Diplomacy from the Early Modern Era to the Present. 
bandas de John Philip Sousa gozaron de fama mundial y hubo fenómenos similares en toda América Latina.

Desde fines del siglo XIX las bandas militares estadounidenses empezaron a tocar música en espacios públicos para inculcar hábitos y valores que se consideraban saludables para el individuo y la sociedad: disciplina grupal, convivencia, patriotismo, comportamiento cívico ejemplar. ${ }^{8} \mathrm{~A}$ partir de la década de los años veinte, las bandas militares estadounidenses comenzaron a moldear la conducta y opinión pública por vía de la radio y otros medios de comunicación masiva. También tocaron himnos y música de otros países con el objeto de promocionar el internacionalismo, una doctrina política según la cual los gobernantes y ciudadanos de distintos Estados aspiran a coexistir en paz a pesar de sus diferencias, con la esperanza de disminuir animadversiones como las que desembocaron en la Gran Guerra. Las bandas militares que tocaron música latinoamericana en la Unión Panamericana, por ejemplo, se atuvieron al ideal imperante en aquella época de que la música es una vía idónea para promover el diálogo y la fraternidad universal. Sus apariciones también se consideraron ocasiones adecuadas para mantener a la población al tanto de sucesos políticos notables. En el caso de los conciertos de la Unión Panamericana las bandas militares promocionaron los acuerdos internacionales y los proyectos culturales promovidos por la Unión Panamericana y otras agencias gubernamentales. ${ }^{9}$

Varios conciertos de la Unión Panamericana fueron eventos celebrados a puertas cerradas para beneplácito de altos dignatarios y de miembros de la alta sociedad de Washington que podían darse el lujo de entretener tan altos propósitos internacionalistas. En esos casos, sólo un reducido grupo de solistas y músicos de las bandas militares apareció en escena. Sin embargo, como se aprecia en la segunda de las imágenes del Apéndice B, otros conciertos se celebraban en los jardines de la Unión Panamericana e involucraban a un público mucho más amplio, sobre todo durante el verano. Gracias a la gestión del Consejero Adams y al trabajo de diversas oficinas de los Departamentos de Estado, Guerra y Marina estadounidenses, los conciertos al aire libre de la Unión Panamericana acabaron reuniendo de forma rutinaria a cientos de asistentes y a más de 70 músicos de las tres bandas militares de la capital. La gran agrupación resultante (la "United Service Orchestra") tocó casi todas las piezas orquestales de los conciertos y acompañó a muchos de

\footnotetext{
Warfield, “The March as Musical Drama...”, pp. 290-291.

Algunos de esos proyectos gubernamentales de miras hemisféricas se discuten en Espinosa, Inter-American Beginnings of U.S. Cultural Diplomacy, 1936-1948.
} 
los solistas latinoamericanos invitados. El gran tamaño de esa orquesta permitió magnificar las dimensiones de la música en cuestión y transformar a los conciertos de la Unión Panamericana en eventos espectaculares. De este modo, se invitó al público a familiarizarse con la música y la cultura de países latinoamericanos con los que el gobierno estadounidense quería cultivar buenas relaciones.

Más aún, como se mencionó antes, varios de estos eventos se transmitieron por la radio con el propósito de alcanzar los oídos de un segmento todavía más amplio de la ciudadanía estadounidense. De hecho, el consejero Adams coordinó esfuerzos con la estación de radio de la Marina estadounidense y con varias estaciones comerciales para que las transmisiones de la Unión Panamericana alcanzaran receptores de radio en ciudades europeas y latinoamericanas. Los pocos testimonios que quedan dan la impresión de que los conciertos se escucharon mal y de forma más bien esporádica en esos lugares lejanos, dadas las dificultades técnicas de la época. Sin embargo, lo que interesa destacar aquí es el deseo cada vez más serio de comunicar ideales panamericanos a un público masivo a nivel internacional.

Vistos así, los conciertos panamericanos de fines de los años veinte y principios de los años treinta no sólo iban de la mano con el entretenimiento de las clases acomodadas o con el protocolo del cuerpo diplomático en Washington o con las giras de artistas latinoamericanos en Estados Unidos, sino con una corriente política y cultural que se llamó "progresivismo". Éste fue un movimiento idealista y paternalista financiado por una generación de políticos, educadores y empresarios que buscaba animar el debate público, la participación ciudadana y la conciencia cívica en distintas urbes estadounidenses por medio de fiestas seculares amparadas por el gobierno, como el Día del Trabajo o el Día de Colón. ${ }^{10}$ En ese tipo de festividades masivas la música se presentaba como un acto edificante que cohesionaba y educaba a la nación de forma accesible, constructiva y recreativa. En el caso que nos concierne —o sea, el que derivó en la celebración anual del Día Panamericano a partir de 1931 - la ejecución rutinaria de música latinoamericana buscaba fomentar también una conciencia cívica novedosa: una de aspiraciones internacionalistas a lo largo y ancho del hemisferio occidental.

10 Vaillant, Sounds of Reform, pp. 3-6; Fabre, Heideking, "Introduction”, Fabre, Heideking, Dreisbach (eds.), Celebrating Ethnicity and Nation, pp. 7-9. 


\section{EL PANAMERICANISMO VISTO COMO REFLEJO Y SUSTENTO DE ÓRDENES INTERNACIONALES}

En años recientes han salido a la luz varios libros que escudriñan la historia del uso de la música y otras artes visuales y escénicas en proyectos de ambiciones panamericanas, pero en ninguno de ellos figura la palabra civismo. ${ }^{11}$ La mayoría se enfoca en la propaganda antitotalitaria de la Segunda Guerra Mundial y de la Guerra fría o en la cooptación de industrias culturales, mediáticas y discográficas por parte del Departamento de Estado de los Estados Unidos. Por eso, a pesar de que sus aportes son valiosos, esos autores nos brindan a veces una visión algo parcial y unilateral de la influencia del movimiento panamericano en la creación y difusión musical. En el campo musicológico, por ejemplo, se debate si el gobierno estadounidense fue exitoso difundiendo el ideario liberal estadounidense en América Latina a partir de 1936 con ayuda de programas gubernamentales de difusión e intercambio musical, pero rara vez se investigan otros momentos, actores o puntos de vista.

Desde luego, las prioridades de la política exterior estadounidense también podrían venir a cuento en un examen crítico de los conciertos de la Unión Panamericana de la entreguerra. Una posible hipótesis es que las bandas militares de Washington enaltecieron la música latinoamericana y propagaron un discurso de armonía hemisférica para mejorar la imagen de Estados Unidos y de sus estamentos militares en una era de intervencionismo rapaz en Centroamérica y el Caribe. Sin embargo, sería imprudente quedarse sólo con el punto de vista unilateral estadounidense. Al igual que otras iniciativas de la Unión Panamericana, un organismo internacional financiado por un conjunto de países americanos, los conciertos panamericanos fueron organizados en colaboración con políticos y administradores de América Latina. Así pues, debemos interrogar el propósito y efecto de que se tocara música latinoamericana en Washington con el visto bueno y la participación de varios regímenes latinoamericanos.

Es aquí donde surge la necesidad de redimensionar el panamericanismo como un movimiento de alcance regional. Como es sabido se hace quizás más evidente pues, falta todavía mucho por investigar acerca de la historia del movimiento panamericano en países como Argentina, Chile, México,

${ }^{11}$ En el campo musicológico pueden mencionarse, como ejemplo, Campbell, "Shaping Solidarity”; Fosler-Lussier, Music in America's Cold War Diplomacy. Véase también, en general, Sadlier, Americans All; Fox, Making Art Pan American. 
Cuba o Brasil, todos ellos activos en proyectos interamericanos desde comienzos de siglo XX. La elite positivista de esos países tendía a compartir algunos de los ideales progresistas estadounidenses, así que no sería descabellado plantear un estudio cultural del movimiento panamericano cuyo eje temático fuese la colaboración práctica e ideológica de autoridades políticas y culturales en Norte y Sudamérica.

La aparición de músicos latinoamericanos en Washington en calidad de embajadores culturales es un claro ejemplo de cooperación internacional al servicio del movimiento panamericano. De igual modo podría entenderse la celebración de festivales, exposiciones y conciertos panamericanos en otras ciudades del continente, pues muchos organizadores de eventos panamericanos en América Latina partieron de anhelos políticos y culturales similares a los de la elite progresista de Washington. Es decir, muchas celebraciones panamericanas en América Latina buscaban inculcar valores cívicos e internacionalistas entre sus públicos. De tal modo, podríamos entender el movimiento panamericano como el conjunto de líderes e instituciones americanas que compartieron una agenda cultural progresista e internacionalista en el continente (o sea, como una formación social e ideológica de alcance transnacional) o como el conjunto rutinario de festividades con las que se promocionó esa agenda cultural en distintas urbes americanas (como un calendario teatral, escénico o performativo de orden regional). En mi opinión, música como la que se exhibió en la Unión Panamericana fue valorada por autoridades de su época en distintos países porque fue una forma impactante de representar y sacralizar ciertos ideales comunitarios, así como un método efectivo de apelar a las emociones de centenares de gentes.

Dicho de otro modo, la música puede y suele ser un vehículo de indoctrinamiento - una herramienta de lo que se conoce como poder suave- y su análisis es útil para desenmascarar la ideología de los grupos que la promueven. ${ }^{12}$ Es posible, entonces, que un estudio más profundo de conciertos y festividades panamericanas en Estados Unidos y otros países ayude a dilucidar con más detalle la mentalidad de una elite internacional que promovió el panamericanismo y su visión compartida de un orden regional pacífico y cosmopolita. ${ }^{13}$

12 Para una definición de poder suave, véase Nye, Soft Power, pp. 5-6.

${ }^{13}$ Orden regional se refiere al conjunto de procesos, instituciones, leyes y normas que legitiman un estilo de gobierno regional; véase Morgan, "Regional Security Complexes and Regional Orders”, Lake, Morgan (eds.), Regional Orders, pp. 20-44. A principios de siglo veinte solía hablarse de "civilización" para referirse a una visión de un orden internacional pacífico y cooperativo. A mi modo de ver, los individuos que participaban en la Unión Pan- 


\section{LA RESISTENCIA AL ORDEN PANAMERICANO}

Cabría esperar, con todo, que esa visión colectiva de hermandad panamericana y las emociones que despertó no fueron siempre del gusto de todos. Concluyamos este texto, pues, con una reflexión sobre la posibilidad de que algunos de estos ideales de cooperación hayan sido impuestos en contra de la voluntad de algunos.

Más allá de su retórica oficial de fraternidad, hay que estar al tanto de que mucha de la energía del movimiento panamericano moderno emanó de impulsos colonialistas y expansionistas en Estados Unidos y de que sus iniciativas se llevaron a cabo en un contexto de crecientes asimetrías de poder en el sistema político y económico internacional. En otras palabras, no es posible hablar de un orden americano compartido sin hacer referencia al marco teórico de relaciones imperiales que Gilbert Joseph y Ricardo Salvatore definieron en sus ya clásicas introducciones al tomo Close Encounters of Empire. ${ }^{14}$ Ahí, el argumento no es tanto que el panamericanismo del siglo $\mathrm{xx}$ fue una imposición del gobierno estadounidense - tesis que muchos escritores y académicos han sostenido desde principios de siglo $\mathrm{xx}$ - sino que centenares de interacciones entre representantes de Estados Unidos y de América Latina ayudaron a edificar una cultura imperial compartida a nivel hemisférico que manifestó discursos, narrativas e identidades históricamente distintivas. Salvatore precisa que el panamericanismo fue ante todo una maquinaria de representación imperial: un conjunto de prácticas e instituciones que aceleró el número de encuentros internacionales entre representantes de países norteamericanos y sudamericanos, ayudando así a difundir y normalizar millares de imágenes, ideas y estereotipos de una América Latina exótica y subdesarrollada frente a cierta idea de modernidad.

Pues bien: una de las dimensiones de encuentro cultural interamericano que Joseph y Salvatore omiten casi por completo en su publicación ya clásica es la que ha quedado apuntada en este breve texto, a saber, la centralidad de las fiestas, ceremonias y representaciones musicales y escénicas en la operación rutinaria de las maquinarias de representación panamericana y en la formación de sus idearios e imaginarios imperiales. Sugiero que una investi-

americana o dialogaban con ella conformaban una sociedad internacional cuya meta declarada, al menos en papel, era la instauración de ese orden civilizatorio en el continente americano. Con tal discurso, sentaron precedentes ideológicos de la corriente que años después se llamaría internacionalismo liberal.

14 Joseph, “Close Encounters...”, Joseph, LeGrand, Salvatore (eds.), Close Encounters of Empire, pp. 3-46; Salvatore, “The Enterprise of Knowledge...”, ibíd., pp. 69-106. 
gación a fondo de la historia de la programación musical en la Unión Panamericana ofrece una oportunidad espléndida para introducir un componente sonoro y performativo al corpus teórico e historiográfico de los encuentros imperiales en el continente.

Después de todo: ¿Qué una serie regular de conciertos latinoamericanos en la capital estadounidense no operó, al igual que ciertas industrias cinematográficas, como una maquinaria circuladora de ideas, imágenes y sonidos evocadores de América Latina, su cultura y su folklor y, por tanto, como definidora de ideas de "lo latinoamericano" en el imaginario colectivo? ¿Qué no fue la Unión Panamericana, entendida como sala de conciertos y punto de encuentro de distintos grupos sociales, emisarios diplomáticos y entusiastas de las artes, un dinámico espacio de debate de similitudes y diferencias culturales en el corazón de la metrópolis imperial? Y, más allá de sus funciones protocolarias, ¿qué no sería la ejecución de música latinoamericana a manos de la Banda de la Marina estadounidense una representación palpable, visible y audible, del encuentro igual y desigual de las instituciones y tradiciones musicales estadounidenses y las de los países latinoamericanos en su zona de dominio formal e informal?

Sólo una investigación más a fondo de los conciertos de la Unión Panamericana revelará si los arreglos musicales de las bandas militares estadounidenses causaron un genuino sentimiento de solidaridad internacional o si también hubo incredulidad e incluso repudio hacia dichos experimentos y a la visión de orden internacional que acompañaban. Las reseñas existentes dejan claro que cientos de personas asistieron con regularidad a los conciertos panamericanos hasta la década de 1950. Millares más los escucharon por la radio. El público difícilmente pudo ser indiferente a la música sonora y festiva de una banda militar de setenta integrantes. He ahí otra fuente del poder característico de ciertas modalidades de ejecución musical: su capacidad de imponerse en el espacio público y forzar encuentros auditivos incluso a regañadientes.

\section{BibLIOGRAFÍA}

Ahrendt, Rebekah, Mark Ferraguto y Damien Mahiet (eds.), Music and Diplomacy from the Early Modern Era to the Present, Nueva York, Palgrave Macmillan, 2014.

Campbell, Jennifer L., "Shaping Solidarity: Music, Diplomacy, and Inter-American Relations, 1936-1946”, tesis de doctorado, University of Connecticut, 2010.

Espinosa, J. Manuel, Inter-American Beginnings of U.S. Cultural Diplomacy, 19361948, Washington, D.C., Department of State Publications, 1976. 
Fabre, Geneviève y Jürgen Heideking, “Introduction”, Celebrating Ethnicity and Nation: American Festive Culture from the Revolution to the Early Twentieth Century, Geneviève Babre, Jürgen Heideking y Kai Dreisbach (eds.), Nueva York y Oxford, Berghahn Books, 2001, pp. 1-24.

Fosler-Lussier, Danielle, Music in America's Cold War Diplomacy, Berkeley y Los Ángeles, University of California Press, 2015.

Fox, Claire F., Making Art Pan American: Cultural Policy and the Cold War, Minneapolis, University of Minnesota Press, 2013.

Gienow-Hecht, Jessica C.E., "Decentering American History”, Decentering America, Jessica C.E., Gienow-Hecht (ed,.), Nueva York y Oxford, Berghahn Books, 2007, pp. 1-22.

Graham, Sarah Ellen, Culture and Propaganda: The Progressive Origins of American Public Diplomacy, 1936-1953, Nueva York, Routledge, 2015.

Hess, Carol A., "Carlos Chávez and Ur-Classicism”, Representing the Good Neighbor: Music, Difference, and the Pan American Dream, Nueva York y Oxford, Oxford University Press, 2013, pp. 25-49.

Joseph, Gilbert M., “Close Encounters: Toward a New Cultural History of U.S.Latin American Relations”, Close Encounters of Empire: Writing the Cultural History of U.S.-Latin American Relations, Gilbert M. Joseph, Catherine C. LeGrand y Ricardo D. Salvatore (eds.), Durham y Londres, Duke University Press, 1998, pp. 3-46.

Madrid, Alejandro L., "Why Music and Performance Studies? Why Now?: An Introduction to the Special Issue”, Trans: Revista Transcultural de Música 13, 2009, $\quad<$ http://www.sibetrans.com/trans/article/1/why-music-andperformance-studies-why-now-an-introduction-to-the-special-issue>, consultado el 20 de noviembre de 2018.

Morgan, Patrick M., "Regional Security Complexes and Regional Orders”, Regional Orders: Building Security in a New World, David A. Lake y Patrick M. Morgan (eds.), University Park, Pennsylvania State, University Press, 1997, pp. 20-44.

Nye, Joseph S., Soft Power: The Means to Success in World Politics, Nueva York, PublicAffairs, 2004.

Pereira Salas, Eugenio, Notes on the History of Music Exchange between the Americas before 1940, Washington D.C., Music Division, Pan American Union, 1943.

Pita González, Alexandra (comp.), Redes intelectuales transnacionales en América Latina durante la entreguerra, México, Universidad de Colima, M.A. Porrúa, 2016.

Sadlier, Darlene J., Americans All: Good Neighbor Cultural Diplomacy in World War II, Austin, The University of Texas Press, 2012. 
Salvatore, Ricardo, D., “The Enterprise of Knowledge: Representational Machines of Informal Empire”, Close Encounters of Empire: Writing the Cultural History of U.S.-Latin American Relations, Gilbert M. Joseph, Catherine C. LeGrand y Ricardo D. Salvatore (eds.), Durham y Londres, Duke University Press, 1998, pp. 69-106.

Vaillant, Derek, Sounds of Reform: Progressivism \& Music in Chicago, 1873-1935, Chapel Hill, The University of North Carolina Press, 2003.

Warfield, Patrick, "The March as Musical Drama and the Spectacle of John Philip Sousa”, Journal of the American Musicological Society 64, no. 2, 2011, pp. 289-318.

Weber, William, The Great Transformation of Musical Taste: Concert Programming from Haydn to Brahms, Nueva York, Cambridge University Press, 2008. 


\section{ApÉNDICE A}

\section{UNION OF AMERICAN REPUBLICS CONCERT OF LATIN AMERICAN MUSIC BY}

The United Service Orchestra and

Manuel Salazar, Tenor

Luis A. Delgadillo, Composer-Pianist

at the Pan American Union, Hall of the Americas

Monday evening, April 21, 1930, 9:00 pm

1. Marimba Solos

Pasillo “Olaya Herrera” Hernando Rico (Colombia)

(Dedicated to the President-Elect of Colombia) (First Rendition)

Habanera "Tú" Eduardo Sánchez de Fuentes (Cuba)

Master Sergeant John Bauman, U.S. Army Band

Harry Wagner, Accompanist

2. "Danza Salvaje”

Luis A. Delgadillo (Nicaragua)

United Service Orchestra, Conducted by the Composer

3. Symphonic Divertissement: “Corazón Latino"

(First rendition)

Characteristic “Yaqui Dance” Alberto Alvarado (Mexico)

United Service Orchestra

Captain William J. Stannard, Leader, U.S. Army Band, Conducting

4. Piano Solo:

"Remembrances of Monimbó” Luis A. Delgadillo (Nicaragua)

Luis A. Delgadillo

5. Grand Fantasia of the opera "Lo Schiavo" Carlos Gomes (Brasil)

(First Rendition in the United States)

Dance “Inca Step” Carlos Valderrama (Peru)

United Service Orchestra

Lieutenant Charles Benter, Leader, U.S. Navy Band, Conducting 
6. Tone Poem: "Voice of the Streets" Humberto Allende (Chile) (First Rendition by this Orchestra)

The composition is very modern in construction, being featured by frequent changes of tempo, and the composer in order to convey his ideas of how the themes used were inspired, has set down in the conductor's score notations in Spanish which when freely translated are the cries of street vendors selling their wares: "Buy pears and peaches" — "Meat fritters red hot with raisins, olives and eggs" — "Yellow clams and little fish"

“Indigenous Mayan Minuet” Maestro Castillo (Guatemala)

United Service Orchestra

Captain Taylor Branson, Leader, U.S. Marine Band, Conducting

7. Vocal Solos:

"Olvido"

"Ay del Ay"

Julio Osma (Costa Rica)

"Morir por tu amor"

B[elisario] de J[esús] García (Mexico)

Manuel Salazar, Tenor

George H. Wilson, Accompanist

8. Symphonic Lyric Legend "Espíritus Incaicos” Pedro Traversari

(Ecuador)

United Service Orchestra

Captain Stannard, Conducting

9. Piano Solo:

"Tipitapa"

Luis A. Delgadillo (Nicaragua)

Luis A. Delgadillo

10. Evocation "Night in the Andes"

(First Rendition)

"Dance and Ritual"

Justin Elie (Haiti)

United Service Orchestra

Lieutenant Benter, Conducting 
11. Vocal Solos: Waltz "Nelly" Horacio Bates (Argentina)

Ballad "La Golondrina" M. [Narciso] Serradell (México)

Manuel Salazar, Tenor

12. Reverie “The Enchanted Hour” Renaldo Hahn (Venezuela)

United Service Orchestra,

Captain Branson, Conducting

13. The Star Spangled Banner

Fuente: Washington D.C. Historical Society. 


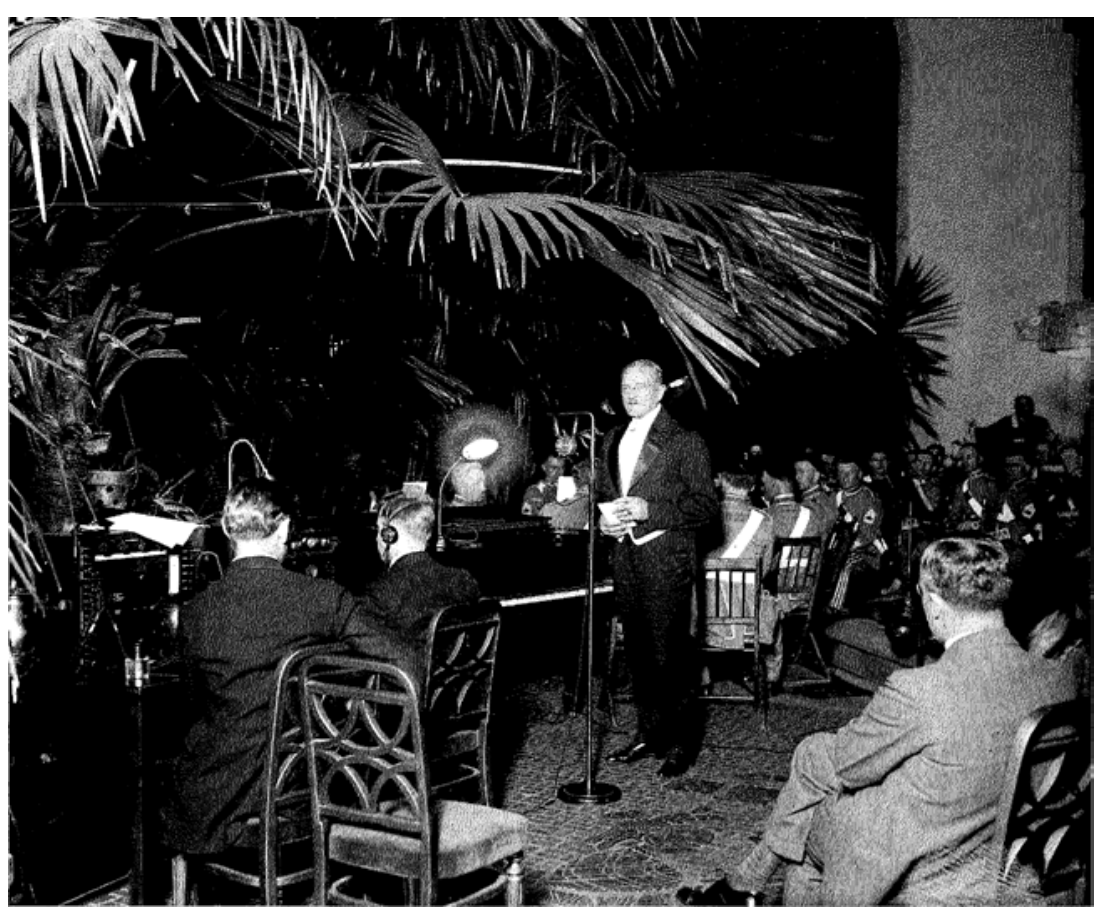

El General Pershing habla por la radio sobre sus experiencias en América Latina durante el concierto de la Unión Panamericana del 23 de abril de 1925.

Fuente: Colección personal del autor. 


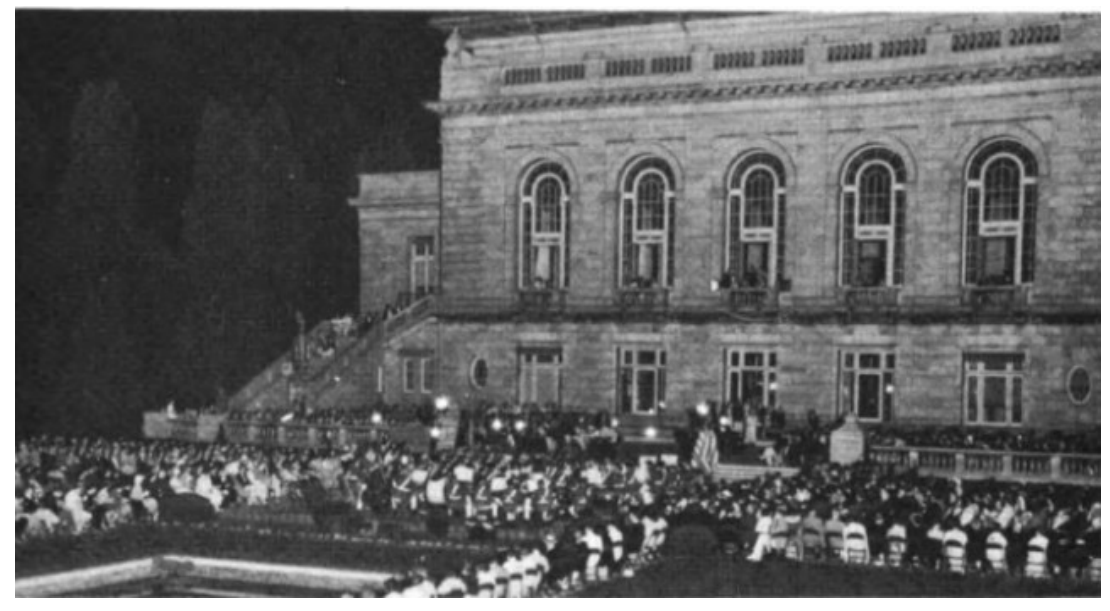

Concierto en el Jardín Azteca de la Unión Panamericana, fecha incierta.

Fuente: $\quad$ Rowe, L.S., The Pan American Union and the Pan American Conferences, Washington D. C., Pan American Union, 1940, p. 13. 